\title{
Nasal symptoms in patients with NSAID hypersensitivity*
}

\author{
B. Lange', C.G. Mortz², C. Bindslev-Jensen², A.D. Kjeldsen' \\ ' Department of Otorhinolaryngology, Odense University Hospital, Odense, Denmark \\ 2Department of Dermatology and Allergy Centre, ORCA (Odense Research Centre for Anaphylaxis), \\ Odense University Hospital, Odense, Denmark
}

Rhinology Online, Vol 2: 91 - 96, 2019

http://doi.org/10.4193/RHINOL/19.009

*Received for publication:

February 23, 2019

Accepted: June 6, 2019

Published: June 12, 2019

\begin{abstract}
Background: Approximately 1 to $2 \%$ of the general population suffers from nonsteroidal anti-inflammatory drugs (NSAID) hypersensitivity. NSAID hypersensitivity is closely associated with concomitant respiratory disease. Exact knowledge of sino-nasal symptoms among patients with NSAID hypersensitivity is important as patients with NSAID hypersensitivity are at risk of having underdiagnosed, undertreated chronic rhinosinusitis with affected QoL. The aim of this study was to estimate the prevalence of chronic rhinosinusitis in patients with NSAID hypersensitivity and to evaluate QoL and the need of ENT intervention.
\end{abstract}

Methodology: Patients with confirmed NSAID hypersensitivity at the Allergy Centre were referred to the Department of Otorhinolaryngology for evaluation by an ENT specialist. All patients completed the Sino Nasal Outcome test 22 (QoL) and underwent nasal endoscopy and smell test.

Results: A total of 46 patients with NSAID hypersensitivity participated in ENT evaluation. Chronic rhinosinusitis was diagnosed in 19 patients. The mean Sino Nasal Outcome test 22 score was 39 in patients with chronic rhinosinusitis and 17 in patients without chronic rhinosinusitis. The sense of smell was decreased in patients with chronic rhinosinusitis. Nasal steroid was indicated in 22 patients. Seven patients had former sinus surgery and 10 patients underwent new sinus or nasal surgery.

Conclusion: With a prevalence of $41 \%$ more than one third of patients with NSAID hypersensitivity have chronic rhinosinusitis with decreased QoL. In patients with sino-nasal problems medical and surgical advice and treatment is important. It is recommended that patients with NSAID hypersensitivity are screened for sino-nasal symptoms and referred for ENT evaluation.

Key words: chronic rhinosinusitis, NSAID hypersensitivity, quality of life

\section{Introduction}

Hypersensitivity to aspirin/acetylsalicylic acid (ASA) and other nonsteroidal anti-inflammatory drugs (NSAID) has a prevalence of $1-2 \%$ in the general population ${ }^{(1)}$. It manifests with a variety of reactions involving skin, respiratory tract and anaphylaxis. International collaborative efforts have provided a framework by which the reactions can be classified into 5 reaction types (EAACl/ENDA guidelines $\left.{ }^{(2)}\right)$. According to the classification system the majority of patient with CRS and NSAID hypersensitivity will be classified as having NSAIDs-exacerbated respiratory disease
(NERD). In NERD the hypersensitivity reaction manifests primarily as bronchial obstruction, dyspnea, and nasal congestion/ rhinorrhea in patients with an underlying chronic airway respiratory disease (asthma/rhinosinusitis). The exposure to NSAID does not initiate the chronic underlying respiratory inflammation but rather exacerbates clinical manifestations of the disease (3). Among patients with asthma and chronic rhinosinusitis (CRS) with nasal polyps the prevalence of NSAID hypersensitivity is 20 to $42 \%{ }^{(4,5)}$. However, no exact estimation of nasal symptoms among patients with NSAID hypersensitivity has been published 
lately.

Being aware of the relationship between NSAID hypersensitivity and respiratory tract disease, clinical history of a patient with NSAID hypersensitivity should include questions on sino-nasal and respiratory symptoms. Patients with CRS have reduced Quality of life (QoL) which can be improved through ENT consultation including patient information and treatment ${ }^{(6)}$ and emphasizes the importance of identifying patients CRS. Management of CRS in patients with NSAID hypersensitivity should follow guidelines. In this study CRS diagnosis and management was based on the European guidelines (EPOS-2012) ${ }^{(7)}$. The aim of this study, descriptive by design, was to describe the prevalence of CRS with and without polyps (CRSwNP and CRSsNP) in patients with NSAID hypersensitivity and to evaluate QoL and the need of ENT intervention.

\section{Materials and Methods}

In this manuscript NSAID is used as abbreviation for both ASA and NSAID. In the Region of Southern Denmark, comprising 1.2 million inhabitants, patients with a history of NSAID hypersensitivity can be referred to and evaluated at the Allergy Center, Odense University Hospital. Patients are typically referred by their GP, lung specialist, or ENT-specialist. During April 2013 to April 2016 patients with a clinical history of NSAID hypersensitivity referred to the Allergy Center were eligible for inclusion. Sample size of the study was determined by the number of eligible patients. A previous study at the Allergy Center showed that over a 9-year period 149 patient were referred for oral provocation test with NSAID of whom 39 (26\%) had a positive test ${ }^{(8)}$. Therefore, a high sample size was not to be expected. The study was descriptive, based on a clinical setting, and a control group was not included.

All referred patients underwent a carefully clinical history, clinical examination and oral provocation test (OPT) according to guidelines ${ }^{(8)}$. Primary OPT was performed with aspirin at 30 minutes intervals. If positive, no further challenges were performed. If the OPT was negative, the patient was offered an OPT with the culprit NSAID. Besides patients with a positive OPT, patients with a strong clinical history of NSAID hypersensitivity were also included and prospectively referred to the Department of Otorhinolaryngology for further evaluation. In these cases, where challenges were omitted, patients had previously experienced severe anaphylactic reaction to a NSAID without other suspected elicitors. Subtypes of NSAID hypersensitivity were classified according to the EAACI/ENDA classification system ${ }^{(2)}$. Department of Otorhinolaryngology, Odense University Hospital is tertiary referral department in the region of Southern Denmark. At the Department of Otorhinolaryngology patients diagnosed with NSAID hypersensitivity were evaluated by one of two ENT-specialists (Rhinologists) including questions on respiratory tract symptoms, smoking, and previous treatment for sino-nasal symptoms. CRS was diagnosed based on symptoms and nasal rhinoscopy according to the European Position Paper on Rhinosinusitis and Nasal Polyps 2012 (EPOS). Bilateral nasal rhinoscopy was performed using a 30 degree rhinoscope and presence of nasal polyps was recorded. Based on symptom severity and objective findings, indication for medical and/or surgical treatment was decided by the Rhinologist. CT scan was only performed if surgery was indicated. All patients completed the Sino Nasal Outcome test 22 (SNOT 22), a patient-reported outcome measure on disease specific quality of life validated for Danish patients ${ }^{(9)}$. The SNOT 22 score range between 0 and 110 with a higher score indicating large rhinosinusitis-related health burden. Several studies have shown that the SNOT 22 covers more than one construct ${ }^{(10-13)}$. The subdomain structure used in this study was based on the study by Dejaco et al. ${ }^{(11)}$ investigating a European population and correlates closely to the structure previously used in a Danish study ${ }^{(9)}$. The four subdomains was defined as: nasal symptoms (need to blow nose, sneezing, runny nose, cough, post-nasal discharge, thick nasal discharge, facial pain/pressure, nasal obstruction, loss of smell or taste), otologic symptoms (ear fullness, dizziness, ear pain), sleep symptoms (difficulty falling asleep, waking up at night, lack of a good night's sleep, waking up tired, fatigue), emotional symptoms (reduced productivity, reduced concentration, frustrated/restless/irritable, sad, embarrassed). Smell test was performed using Sniffin' sticks, screening 12, from Burghart medical technology ${ }^{(14)}$. It is an identification test by design, meaning that 12 scents must be identified by the participant. The result is a score between 0 and 12 with 0 indicating no correct answers and 12 indicating all correct answers.

\section{Statistical methods}

The Chi-squared test was used for comparison of frequency distribution. The difference in SNOT 22 score and smell score between patients with and without CRS and between CRSsNP and CRSwNP was analyzed using Mann-Whitney $U$ test. P-value $<0.05$ was considered statistically significant.

\section{Results}

A total of 54 patients were available for participation of whom 46 patients participated after obtaining their written consent. Mean age of participants were 44 years, number of females/ males were $23 / 23,37 \%$ were smokers and $39 \%$ had asthma based on interview. A positive challenge to ASA was found in 26 (57\%) patients with a cumulative dosage ranging from $55 \mathrm{mg}$ to $1155 \mathrm{mg}$ with a mean value at $671 \mathrm{mg}$. A negative challenge to ASA but a positive challenge to the culprit NSAID was found in 9 (20\%) patients; 3 patients to diclofenac with a cumulative dosage between $55.5 \mathrm{mg}$ and $111 \mathrm{mg}, 2$ patients to naproxen with a cumulative dosage of $55 \mathrm{mg}$ respectively $555 \mathrm{mg}$, and 4 patients to ibuprofen with a cumulative dosage between $6 \mathrm{mg}$ 
Table 1. Characteristics of 46 patients with NSAID hypersensitivity according to the EAACI/ENDA classification.

\begin{tabular}{|c|c|c|c|c|c|c|}
\hline Type of reaction & $\begin{array}{l}\text { Clinical } \\
\text { manifestation }\end{array}$ & $\begin{array}{l}\text { Timing of } \\
\text { reaction }\end{array}$ & $\begin{array}{l}\text { Underlying } \\
\text { disease }\end{array}$ & Cross-reactivity & $\begin{array}{l}\text { Putative } \\
\text { mechanism }\end{array}$ & $\begin{array}{l}\text { Patients (number } \\
\text { having CRS) }\end{array}$ \\
\hline $\begin{array}{l}\text { NSAIDs-exacerbated } \\
\text { respiratory disease } \\
\text { (NERD) }\end{array}$ & $\begin{array}{l}\text { Broncial obstruction, } \\
\text { dyspnea and/or } \\
\text { nasal congestion/ } \\
\text { rhinorrhea }\end{array}$ & Acute & $\begin{array}{l}\text { Asthma/ } \\
\text { rhinosinusitis/ } \\
\text { nasal polyps }\end{array}$ & Cross-reactive & $\begin{array}{l}\text { Non-allergic } \\
\text { COX-1 inhibition }\end{array}$ & $14^{*}(13)$ \\
\hline $\begin{array}{l}\text { NSAIDs-exacerbated } \\
\text { cutaneous disease } \\
\text { (NECD) }\end{array}$ & $\begin{array}{l}\text { Wheals and/or } \\
\text { angioedema }\end{array}$ & - & $\begin{array}{l}\text { Chronic urti- } \\
\text { carial }\end{array}$ & Cross-reactive & $\begin{array}{l}\text { Non-allergic } \\
\text { COX-1 inhibition }\end{array}$ & $6^{* *}(1)$ \\
\hline $\begin{array}{l}\text { NSAIDs-induced } \\
\text { urticarial/angioe- } \\
\text { dema (NIUA) }\end{array}$ & $\begin{array}{l}\text { Wheals and/or } \\
\text { angioedema }\end{array}$ & - & $\begin{array}{l}\text { No underlying } \\
\text { chronic disease }\end{array}$ & Cross-reactive & $\begin{array}{l}\text { Non-allergic un- } \\
\text { known, probably } \\
\text { COX-1 inhibition }\end{array}$ & $19 * * *(2)$ \\
\hline $\begin{array}{l}\text { Single NSAID- } \\
\text { induced urticarial/ } \\
\text { angioedema and } \\
\text { anaphylaxis } \\
\text { (SNIUAA) }\end{array}$ & $\begin{array}{l}\text { Wheals/ } \\
\text { angioedema/ } \\
\text { anaphylaxis }\end{array}$ & - & $\begin{array}{l}\text { No underlying } \\
\text { chronic disease }\end{array}$ & $\begin{array}{l}\text { Single drug } \\
\text { induced }\end{array}$ & $\begin{array}{l}\text { Allergic lgE- } \\
\text { mediated }\end{array}$ & $7(3)$ \\
\hline $\begin{array}{l}\text { Single-NSAID } \\
\text { induced delayed } \\
\text { reactions (SNIDR) }\end{array}$ & $\begin{array}{l}\text { Various symptoms } \\
\text { and organs involved } \\
\text { (e.g. fixed drug } \\
\text { eruption, SJS/TEN, } \\
\text { nephritis) }\end{array}$ & Delayed & $\begin{array}{l}\text { No underlying } \\
\text { chronic disease }\end{array}$ & $\begin{array}{l}\text { Single drug or } \\
\text { multiple drug } \\
\text { induced }\end{array}$ & $\begin{array}{l}\text { Allergic T-cell } \\
\text { mediated }\end{array}$ & 0 \\
\hline
\end{tabular}

*Six patients had overlap of cutaneous symptoms, ** One patient had overlap of respiratory symptoms, ${ }^{* *}$ Two patients had overlap of respiratory symptoms.

and $666 \mathrm{mg}$. Eleven patients had a history with severe anaphylaxis to NSAID without other suspected elicitors and OPT was omitted due to safety in these patients. All patients were classified according to the EAACI/ENDA guidelines (Table 1). Using the EAACI/ENDA guidelines 6 patients in the NERD group also had cutaneous symptoms and in the NECD and NIUA group 3 patients also had respiratory symptoms. As expected, most patients with CRS were in the NERD group. According to the EAACI/ENDA guideline 14 was classified as NERD, however, 1 persosn had no CRS but only asthma, and 2 of those with CRS had no visible polyps at rhinoscopy.

Before inclusion in the study 14 of the 46 participants were in treatment with nasal steroid. Another 10 patients were recommended nasal steroid after examination by the ENT specialist. Besides chronic rhinosinusitis nasal steroid was recommended in patients with symptoms of allergic rhinitis. Seven patients had former nasal or sinus surgery of whom 5 patients underwent renewed sinus surgery. Three patients underwent primary sinus surgery and 2 patients underwent septum surgery. All patients receiving sinus surgery were diagnosed with NERD. CRS was diagnosed in 19 of the 46 patients resulting in a prevalence of CRS at 41\%, 12 with CRSwNP and 7 with CRSsNP. Table 2 shows data comparing patients with and without CRS. CRS was split into CRSwNP and CRSsNP for comparison. There was no significant difference in age, sex and smoking between the groups. Patients with CRS had significant higher SNOT 22 score and significant lower smell score and asthma was more prevalent in patients with CRS. Comparing CRSwNP and CRSsNP there was no difference in asthma, SNOT 22 total score and number of patients receiving nasal steroid; Smell score was significant lower in patients with CRSwNP. Most patients with CRS was treated with nasal steroid, and sinus surgery was only performed in patients with CRSwNP. Two patients without CRS had septum plasty performed. Table 3 shows mean scores of the SNOT 22 and the SNOT 22 subdomains. Patients with CRS had significant higher scores in all subdomains compared to patients without CRS and CRSwNP had significant higher score in nasal symptoms compared to CRSsNP.

\section{Discussion}

\section{Prevalence}

This study describes a high CRS prevalence of $41 \%$ and a prevalence of polyps of $26 \%$ in patients with NSAID hypersensitivity. This is markedly higher compared to the CRS prevalence of $9 \%$ in the Danish background population ${ }^{(15)}$. Because of radiation hygiene, a CT scan was only performed if surgery was indicated. A prevalence of CRS in NSAID hypersensitivity at 36-96\% as described in EPOS ${ }^{(7)}$, was based on studies from the 1970s with an outdated definition of NSAID hypersensitivity and CRS. In this study OPT was used for the diagnosis of NSAID hypersensitivity and CRS was diagnosed according to the EPOS criteria from 2012 including clinical examination and rhinoscopy. Both CRS with and without polyps were diagnosed; CRS with polyps being the most prevalent. The overall high prevalence of CRS in NSAID 
Table 2. Results comparing patients with and without CRS and patients with CRSwNP and CRSsNP (Range).

\begin{tabular}{|c|c|c|c|c|c|c|}
\hline & No CRS & CRS overall & $\mathbf{p}$ & CRSsNP & CRSwNP & $\mathbf{p}$ \\
\hline Number of patients & 27 & 19 & - & 7 & 12 & - \\
\hline Mean age & $43(20-75)$ & $44(19-65)$ & 0.89 & $47(33-60)$ & $42(19-65)$ & 0.45 \\
\hline Female & 13 & 10 & 0.77 & 4 & 6 & 0.76 \\
\hline Current smokers & 11 & 6 & 0.53 & 2 & 4 & 0.83 \\
\hline Asthma & 3 & 15 & 0.00 & 4 & 11 & 0.08 \\
\hline SNOT 22 score & $17(0-49)$ & 39 (7-77) & 0.00 & $34(24-42)$ & $42(7-77)$ & 0.07 \\
\hline Smell test score & $10(6-12)$ & $7(0-12)$ & 0.01 & $11(10-12)$ & $5(0-11)$ & 0.00 \\
\hline Previous sinus surgery & 0 & 7 & 0.00 & 0 & 7 & 0.01 \\
\hline Number of patients receiving nasal steroid & 2 & 12 & 0.00 & 3 & 9 & 0.16 \\
\hline Number of patients receiving nasal/sinus surgery & $2^{*}$ & 8 & 0.01 & 0 & 8 & 0.01 \\
\hline
\end{tabular}

* Only septumplasty.

Table 3. Mean score SNOT 22 total and mean score SNOT 22 subdomains.

\begin{tabular}{|c|c|c|c|c|c|c|}
\hline & No CRS & CRS overall & $\mathbf{p}$ & CRSsNP & CRSwNP & $\mathbf{p}$ \\
\hline SNOT 22 total & 17 & 39 & 0.00 & 34 & 42 & 0.07 \\
\hline Nasal symptoms & 7.9 & 20,7 & 0.00 & 16.1 & 23.3 & 0.04 \\
\hline Otologic symptoms & 1.3 & 2.7 & 0.01 & 2.3 & 2.9 & 0.32 \\
\hline Sleep symptoms & 4.8 & 8.5 & 0.02 & 8.6 & 8.4 & 0.97 \\
\hline Emotional symptoms & 2.6 & 7.3 & 0.00 & 6.9 & 7.5 & 0.97 \\
\hline
\end{tabular}

Maximum range: SNOT 22 total: 0-110, nasal symptoms: 0-45, otologic symptoms: 0-15, sleep symptoms: 0-25, emotional symptoms: 0-25.

hypersensitivity underlines the importance of questioning the patients about sino-nasal symptoms during investigation of NSAID hypersensitivity. Based on interview the prevalence of asthma was $39 \%$ in patients with NSAID hypersensitivity. Further examination and evaluation of asthma was not included in this paper.

\section{Quality of life}

It is well known that CRS has a negative impact on QoL which can be measured using SNOT 22. In this study, patients with NSAID hypersensitivity and CRS showed a mean SNOT 22 score at 39. This is markedly higher than the mean SNOT 22 score at 10 in the Danish population without CRS ${ }^{(16)}$ used as the Danish reference value. The SNOT 22 score found in this study is also higher than the mean score at 28 among patients with CRS in the general Danish population ${ }^{(15)}$ and it is comparable with a score at 44 among patients with CRS referred for surgery ${ }^{(17)}$. This indicates that the evaluation of sino-nasal problems in patients with NSAID hypersensitivity is very important to identify those with rhinosinusitis related health burden. A VAS-scale was not applied in this study. Using a study design with a control group might have strengthened the results. This study describes CRSwNP and CRSsNP. However, this differentiation is often not possible at Allergy Centers without the presence of an ENT spe-
cialist/Rhinologist. Therefore, further evaluation by an ENT specialist in patients with sino-nasal symptoms is recommended.

\section{CRS and treatment}

Nasal steroid was indicated in 24 out of 46 patients with NSAID hypersensitivity and 10 patients underwent surgery after ENT evaluation. Only patients with CRSwNP had sinus surgery performed. Numerous studies have shown the benefit of medical and surgical treatment in patients with CRS with and without polyps ${ }^{(18)}$. Indication of treatment is based on symptoms/QoL and ENT examination. In this study, indication and decision on the need of medical and/or surgical treatment was made according to the expertise of two experienced Rhinologist. Alternatively, the decision could be based on pre-specified criteria.

Screening the population of patients with NSAID hypersensitivity could identify those in need of ENT evaluation and treatment. The structure and content of such screening can be adjusted according to local possibilities. Following this study, our study group recommends the use of a questionnaire on sino-nasal symptoms together with the SNOT 22 to pinpoint patients to be referred for ENT evaluation and indication for medical and surgical treatment. 
In this study 35 patients had a positive OPT and 11 patients were included based on a clear-cut history with anaphylaxis in connection with NSAID intake and other culprits excluded. NSAID hypersensitivity is diagnosed based on a clinical history and if possible, an NSAID challenge. For those in whom NSAID sensitivity is suspected but not definite, an NSAID challenge is the only definitive method of diagnosis. However, provocation with a culprit drug is controversial in patients with a history of severe reactions and the benefit of an oral provocation test should be weighed against the risk involved ${ }^{(19)}$. Classification of NSAID hypersensitive patients according to the EAACI/ENDA guidelines is no simple task being based on thorough knowledge of the clinical history and underlying disease combined with results of OPT. As previously described ${ }^{(2,8)}$ coexistence of cutaneous and airway symptoms is challenging and was also the case in 9 patients in this study. It is also challenging categorizing patients with clinical respiratory manifestation who only have asthma or CRSwNP if NERD is defined having both. Classification of the patients was not within the aim of this study and sample size was too small for subgroup evaluation. However, it was interesting to show the distribution and as expected most patients with CRS were in the NERD group. Evaluation of the classification system awaits future discussion.

\section{Conclusion}

In patients with NSAID hypersensitivity $41 \%$ had CRS with affected QoL, reduced sense of smell and the need of treatment for sino-nasal problems. It is recommended that patients with NSAID hypersensitivity are screened for sino-nasal symptoms and evaluated for ENT reference to improve their QoL.

\section{Acknowledgement}

Not applicable.

\section{Authorship contribution}

Authorships are assigned according to the ICMJE authorship criteria. All authors read and approved the final manuscript. CM and $C B J$ were responsible of investigating the patients at the Allergy Center and referring the patients to the Department of Otorhinolaryngology. AK and BL examined the patients at the Department of Otorhinolaryngology. BL collected and interpreted the patient data in collaboration with $\mathrm{CM}$.

\section{Conflict of interest}

The authors have no conflicts of interest to declare.

\section{Ethics approval and consent to participate}

The study was approved by the Danish Data Protection Agency and by the Regional Ethics Committee, ID S-20160003. All participants gave their written consent.

\section{Consent for publication}

Not applicable.

\section{Availability of data and materials}

The datasets used during the current study are available from the corresponding author on reasonable request.

\section{Funding}

Not applicable.

List of abbreviations. ASA: aspirin/acetylsalicylic acid, CRS: chronic rhinosinusitis, CRSwNP: chronic rhinosinusitis with nasal polyps, CRSsNP: chronic rhinosinusitis without nasal polyps, EAACI: European academy of allergy and clinical immunology, ENDA: European network on drug allergy, ENT: ear, nose, and throat, EPOS: European Position Paper on Rhinosinusitis and Nasal Polyps, NECD: NSAIDs-exacerbated cutaneous disease, NERD: NSAIDsexacerbated respiratory disease, NIUA: NSAIDs-induced urticarial/angioedema, NSAID: nonsteroidal anti-inflammatory drugs, OPT: oral provocation test, QoL: quality of life, SNOT 22: sino nasal outcome test 22.

\section{References}

1. Settipane RA, Constantine HP, Settipane GA. Aspirin intolerance and recurrent urticaria in normal adults and children. Epidemiology and review. Allergy. 1980;35(2):149-54.

2. Kowalski ML, Asero R, Bavbek S, Blanca M, Blanca-Lopez N, Bochenek G, et al. Classification and practical approach to the diagnosis and management of hypersensitivity to nonsteroidal anti-inflammatory drugs. Allergy. 2013;68(10):1219-32.

3. Laidlaw TM, Cahill KN. Current Knowledge and Management of Hypersensitivity to Aspirin and NSAIDs. Allergy Clin Immunol
Pract. 2017;5(3):537-45.

4. Kim JE, Kountakis SE. The prevalence of Samter's triad in patients undergoing functional endoscopic sinus surgery. ENT J. 2007:86(7):396-9.

5. White AA, Stevenson DD. AspirinExacerbated Respiratory Disease. N Engl J Med. 2018;379(11):1060-70.

6. Lange B, Thilsing T, Baelum J, Pedersen OF, Holst R, Kjeldsen AD. Do patients with chronic rhinosinusitis benefit from consultation with an ENT-doctor? Acta Otolaryngol. 2015;135(7):706-12.

7. Fokkens WJ, Lund VJ, Mullol J, Bachert C, Alobid I, Baroody F, et al. European Position
Paper on Rhinosinusitis and Nasal Polyps 2012. Rhinology Suppl. 2012(23):3 p preceding table of contents, 1-298.

8. Nissen CV, Bindslev-Jensen C, Mortz CG. Hypersensitivity to non-steroidal antiinflammatory drugs (NSAIDs): classification of a Danish patient cohort according to EAACI/ENDA guidelines. Clin Transl Allergy. 2015;5:10.

9. Lange B, Thilsing T, Al-kalemji A, Baelum J, Martinussen T, Kjeldsen A. The Sino-Nasal Outcome Test 22 validated for Danish patients. Dan Med Bull. 2011;58(2):A4235.

10. DeConde AS, Bodner TE, Mace JC, Smith TL. Response shift in quality of life after endo- 
scopic sinus surgery for chronic rhinosinusitis. JAMA Otolaryngol Head Neck Surg. 2014;140(8):712-9.

11. Dejaco D, Riedl D, Huber A, Moschen R, Giotakis Al, Bektic-Tadic L, et al. The SNOT22 factorial structure in European patients with chronic rhinosinusitis: new clinical insights. Eur Arch Otorhinolaryngol. 2019;276(5):1355-65.

12. Sedaghat AR, Gray ST, Caradonna SD Caradonna DS. Clustering of chronic rhinosinusitis symptomatology reveals nove associations with objective clinical and demographic characteristics. Am J Rhinol Allergy. 2015;29(2):100-5.

13. Feng AL, Wesely NC, Hoehle LP, Phillips KM, Yamasaki A, Campbell AP, et al. A validated model for the 22-item Sino-Nasal Outcome Test subdomain structure in chronic rhinosinusitis. Int Forum Allergy Rhinol. 2017;7(12):1140-8.

14. Kobal G, Hummel T, Sekinger B, Barz S, Roscher S, Wolf S. "Sniffin' sticks": screen- ing of olfactory performance. Rhinology. 1996;34(4):222-6.

15. Lange $B$, Holst R, Thilsing T, Baelum J, Kjeldsen A. Quality of life and associated factors in patients with chronic rhinosinusitis in the general population: a prospective questionnaire and clinical cross-sectional study. Clin Otolaryngol. 2013;38(6):474-80.

16. Lange B, Thilsing T, Baelum J, Kjeldsen AD The Sinonasal Outcome Test 22 score in patients without chronic rhinosinusitis. Clin Otolaryngol. 2016;41(2):127-30.

17. Abdalla S, Alreefy H, Hopkins C. Prevalence of sinonasal outcome test (SNOT-22) symptoms in patients undergoing surgery for chronic rhinosinusitis in the England and Wales National prospective audit. Clin Otolaryngol.. 2012;37(4):276-82.

18. Rimmer J, Fokkens W, Chong LY, Hopkins C. Surgical versus medical interventions for chronic rhinosinusitis with nasal polyps. Cochrane Database Syst Rev. 2014:(12):CD006991.
19. Kowalski ML, Makowska JS, Blanca M, Bavbek S, Bochenek G, Bousquet J, et al. Hypersensitivity to nonsteroidal antiinflammatory drugs (NSAIDs) - classification, diagnosis and management: review of the EAACI/ENDA and GA2LEN/HANNA. Allergy. 2011;66(7):818-29.

\section{Bibi Lange}

Department of Otorhinolaryngology

Odense University Hospital

J.B. Winsløws Vej 4

DK-5000 Odense

Denmark

Tel: +4526395265

E-mail: bibi.lange@rsyd.dk

ISSN: 2589-5613 / O2019 The Author(s). This work is licensed under a Creative Commons Attribution 4.0 International License. The images or other third party material in this article are included in the article's Creative Commons license, unless indicated otherwise in the credit line; if the material is not included under the Creative Commons license, users will need to obtain permission from the license holder to reproduce the material. To view a copy of this license, visit http://creativecommons.org/ licenses/by/4.0/ 